\title{
Letters
}

Website: bmj.com

Email: letters@bmj.com

\section{Heavy drinking by young British women gives cause for concern}

EDITOR-During October and November 2000 a survey of the drinking patterns of British adults aged 18 and over was carried out. Subjects were selected at 267 geographically representative sampling points in England, Scotland, and Wales. Respondents were selected by an interlocking quota to be representative of the general population in terms of age and sex. In addition, a parallel quota of socioeconomic status was imposed. A standardised schedule was used when respondents were interviewed. Sensitive questions were explored with a computer assisted personal interview. Information was elicited from 2027 people, of whom 1052 were women.

As expected, ${ }^{1}$ there were considerable differences between the sexes in patterns of self reported alcohol consumption. A total of $91 \%$ of men $(n=887)$ and $85 \%$ of women $(\mathrm{n}=890)$ reported that they sometimes consumed beverage alcohol; $80 \%$ of the male drinkers $(\mathrm{n}=707)$ and $65 \%$ of the female drinkers $(\mathrm{n}=582)$ had consumed some alcohol in the previous week.

A surprising difference emerged when the past week's alcohol consumption of women was compared with that of men (table). Among men, those most likely to report that they had been drinking at high risk levels ( $\geqslant 51$ units) were aged 35-54. In contrast, by far the highest proportion of women who were high risk drinkers (consuming $\geqslant 35$ units a week) was among those aged only $18-24$. (A unit is defined as 1 $\mathrm{cl}$, or $7.9 \mathrm{~g}$ absolute alcohol.)

Hibell et al recently reported that young people in the United Kingdom are particularly likely to drink heavily. ${ }^{2}$ Our study suggests that different trends may be developing in the drinking careers of women and men. If this is so the number of younger women developing problems related to alcohol is likely to increase. Women are less likely to attend treatment agencies concerned with alcohol problems. Thus staff working in the types of agencies that young women attend need to be trained in early identification of such problems.

Numbers (percentages) of all respondents drinking at high risk levels

\begin{tabular}{lccccccc} 
& \multicolumn{7}{c}{ Age (years) } \\
\cline { 2 - 8 } Sex & $\mathbf{1 8 - 2 4}$ & $\mathbf{2 5 - 3 4}$ & $\mathbf{3 5 - 4 4}$ & $\mathbf{4 5 - 5 4}$ & $\mathbf{5 5 - 6 4}$ & $\mathbf{6 5 - 7 4}$ & $\geqslant \mathbf{7 5}$ \\
\hline Male & $6(5)$ & $10(5)$ & $13(6)$ & $10(6)$ & $5(4)$ & $3(3)$ & $2(4)$ \\
\hline Female & $9(8)$ & $5(3)$ & $6(3)$ & $5(3)$ & $1(1)$ & 0 & 0
\end{tabular}

These agencies include well woman and antenatal clinics.

Moira Plant codirector

Martin Plant director

Alcohol and Health Research Centre, City Hospital, Edinburgh EH10 5SB

Moiraplant@onet.co.uk

We thank members of the International Research Group on Gender and Alcohol and Bill Mason, senior statistician, for their help. Fieldwork was conducted by NOP Solutions. This study was mainly funded by the Amsterdam Group and the Alcohol Education and Research Council. Additional support was provided by the University of North Dakota and the North British Distillery Company.

1 Plant ML. Women and alcohol: contemporary and historical perspectives. London: Free Association Books, 1997.

2 Hibell B, Andersson B, Ahlstrom S, Balakireva O, Bjarnason T, Kokkevi A, et al. The 1999 ESPAD report:alcohol and other drug use among students in 30 European countries. Stockholm: Swedish Council for Information on Alcohol and Other Drugs, 2001.

\section{Full time forensic pathology service needs to be established}

EDIToR-The investigation of deaths in England and Wales has not been attracting positive headlines recently. Events surrounding Alan Shipman, Alder Hey, Bristol, and the Marchioness incident have all put a question mark over the processes of investigation and have prompted various inquiries, including consideration of the role of coroners.

Currently, coroners may be medical practitioners or lawyers of at least five years' standing. ${ }^{1}$ Many work part time, with small jurisdictions. Despite this, if a complex death or a mass disaster occurs in their jurisdiction, the local coroner, no matter how inexperienced, has to both investigate and adjudicate.

The system in England and Wales has a high rate of necropsies, and $23 \%$ of all deaths are followed by a medicolegal necropsy. ${ }^{2}$ Despite that, Shipman bypassed it while killing his patients. Other parts of the British Isles, not noted for concealed homicide, have a lower necropsy rate-for example, the Republic of Ireland 15\%, Scot- land, 10\%, Northern Ireland, 9.3\% (AW Clotworthy, personal communication). Germany, at $2 \%$, has one of the lowest necropsy rates in western Europe. ${ }^{3}$

There is no doubt that there are serious deficiencies in our system. In his evidence to the Bristol inquiry, the honourable secretary of the Coroner's Society referred to the "quill pen technology" of the modern coroner. In some medicolegal systems the sole responsibility for the investigation of death is vested in a medical examiner, usually a forensic pathologist. It has been suggested that a medical examiner's system should be introduced into England and Wales.

We believe that the strengths of the coroner's system should be retained but coupled with greater medical participation. For example, the necessity for a necropsy should be decided by experienced and appropriately trained doctors who should also be responsible for collecting, correlating, and analysing data, so that any unusual trends would quickly be recognised. They might also be responsible for overseeing certification of cremation, which currently is expensive for relatives and ineffective.

Coroners should still be independent but work full time with larger jurisdictions. They should be legally qualified and concerned with legal rather than investigative matters. Their role should be mainly

\section{Advice to authors}

We prefer to receive all responses electronically, sent directly to our website. Processing your letter will be delayed unless it arrives in an electronic form.

We are now posting all direct submissions to our website within 24 hours of receipt and our intention is to post all other electronic submissions there as well. All responses will be eligible for publication in the paper journal.

Responses should be under 400 words and relate to articles published in the preceding month. They should include $\leqslant 5$ references, in the Vancouver style, including one to the BMJ article to which they relate. We welcome illustrations.

Please supply each author's current appointment and full address, and a phone or fax number or email address for the corresponding author. We ask authors to declare any competing interest. Please send a stamped addressed envelope if you would like to know whether your letter has been accepted or rejected.

Letters will be edited and may be shortened.

bmj.com

letters@bmj.com 
judicial. A full time forensic pathology service needs to be established, which can be seen to be independent of the police and the coronial service and which could function as the regional medical investigator of death.

Christopher Milroy professor of forensic pathology Department of Forensic Pathology, University of Sheffield, The Medico-Legal Centre, Sheffield S3 7ES

c.m.milroy@sheffield.ac.uk

Bill Hunt (retired) president, British Association in Forensic Medicine

Barronhall, St Monans, Fife KY10 2AY

1 Dorries CP. Coromer's courts: a guide to the law and practice. Chichester: Wiley 1999:385.

2 England and Wales Home Office. Statistics of deaths reported to coroners Statistical Bulletin 2000;8/00, April 3 Department of Justice, Equality and Law Reform. Review of the coroner service. Dublin: Stationery Office, 2000 www.justice.ie/80256976002CB7A4/vWeb/

fsWMAK4Q7JKY (accessed 9 Nov 2001).

\section{Nodular thyroid disease}

\section{Abnormal thyroid function may be positive discriminator for malignancy}

EDITOR-Keston Jones states that testing of thyroid function is still one of the cornerstones of investigation in nodular thyroid disease. ${ }^{1} \mathrm{He}$ also states that overt thyroid dysfunction effectively rules out the possibility of malignancy.

Thyroid function tests will not help in the discrimination of a nodule as they give no description of the nodule. In addition, malignancy may occur in patients with hyperthyroidism and a palpable thyroid nodule. Kraimps et al report that in patients with a cold nodule and Graves' disease the incidence of malignancy is as high as $15 \%$, and that malignancy should be taken as an indication for total thyroidectomy, although in this group the nodules were mainly nonpalpable. $^{2}$

More impressively, Carnell and Valente report that $19 \%$ of palpable cold nodules were malignant in a retrospective review of 468 patients with Graves' disease. ${ }^{3}$ Thus in some instances abnormal thyroid function seems to be a positive discriminator for malignancy, although in the most euthyroid patients it will give no further diagnostic information.

G L Sayer specialist registrar in general surgery King's College Hospital, London SE5 9RS gabrielsayer@hotmail.com

1 Keston Jones M. Management of nodular thyroid disease BMJ 2001;323:293-4. (11 August.)

2 Kraimps JL, Bouin-Pineau MH, Mathonnet M, De Calan L, Ronceray J, Visset J, et al. Multicentre study of thyroid nodules in patients with Graves' disease. $\mathrm{Br} J$ Surg 2000;87:1111-3.

3 Carnell NE, Valente WA. Thyroid nodules in Graves disease: classification, characterization, and response to treatment. Thyroid 1998;8:647-52, 1079.

\section{Author's reply}

EDITOR-Sayer's comments are not relevant to the management of nodular thyroid disease. It is recognised that nodules occurring in diffuse Graves' goitres have an increased risk of malignancy and that cancers arising in these goitres may be more aggressive in their behaviour.
A nodule in a patient with Graves' disease would certainly give rise to concern, and the patient would undergo fine needle aspiration cytology. In a hyperthyroid patient with nodular thyroid disease the situation is quite different and the risk of malignancy is $l$ ow $^{2}$; fine needle aspiration cytology does not need to be performed routinely here unless clinical features suggestive of malignancy are present (history of neck irradiation, rapid growth, family history, hard consistency, local lymphadenopathy, and recurrent laryngeal nerve palsy in the absence of previous surgery).

It is unusual for patients with nodular thyroid disease to have hyperthyroidism or hypothyroidism. An abnormal result of a thyroid function test decreases the risk of thyroid cancer in these patients.

M Keston Jones consultant physician

Swansea NHS Trust, Singleton Hospital, Swansea SA2 8QA

keston.jones@swansea-tr.wales.nhs.uk

1 Belfiore A, Garofalo MR, Giuffrida D, Runello F, Filetti S, Fiumara A, et al. Increased aggressiveness of thyroid cancer in patients with Graves' disease. J Clin Endocrinol Metab 1990;70:830-5. 2 Belfiore A, La Rosa GL. Fine-needle aspiration biopsy of the thric

3 American Association of Clinical Endocrinologists. AACE clinical practice guidelines for the diagnosis and management of thyroid nodules. Endocr Pract 1996;2:80-4

\section{Electronic patient records in general practice}

\section{Published methods of measuring the} accuracy of electronic records do exist

EDITor-Hassey et al have highlighted the importance of ensuring that electronic records are accurate. ${ }^{1}$ In their study they explored a method of measuring the validity and utility of electronic records in general practice, including whether the coding of 15 marker diagnoses was a true reflection of the actual prevalence.

They are, however, wrong in their assertion that no published accounts of measuring the validity of electronic record contents exist. Hogan and Wagner performed a literature review and compared 20 articles that met certain quality criteria. ${ }^{2}$ They recommended (as did Hassey et al) that measures of completeness (sensitivity or detection rate) and correctness (positive predictive value) were valuable. These measures have also been shown to be valuable in measuring the quality of data retrieval.

Other measures derived from $2 \times 2$ contingency tables are less likely to be helpful because of the combination of a large total number of records and true negatives. To compensate for this, Hassey et al propose two new descriptive statistics. Previous reports have used Cohen's $\kappa, 4$ a measure of the strength of agreement between the observed retrieval and the gold standard, against a result that might be expected by chance. Cohen's $\kappa$ has the advantage of being a well validated single index and has been shown to be a useful index of measur- ing data retrieval from electronic records where performances of $>0.9$ can be achieved. ${ }^{3}$

When Cohen's $\kappa$ is applied to the data by Hassey et al, it highlights similar priority areas of data concern where the value is $<0.9$ (obesity 0.04, hypothyroidism 0.89 , iron deficiency anaemia 0.86 , asthma 0.86 ). Prescriptions generated were also compared with those dispensed by a local pharmacy. As they were computer generated, $99.7 \%$ were reported to be valid, but of the 10 handwritten prescriptions only $80 \%$ were accurately recorded. Perhaps a more suitable design would have been to check in a sample how many of the prescriptions reflected the correct dose and frequency. Hassey et al claim that the principal innovation of the study was the use of Read codes as the test for the true presence of a diagnosis, despite Gray et al's earlier account of identifying patients with ischaemic heart disease by using a similar technique and reporting exactly the same sensitivity rate $(96 \%) .^{5}$ The approach used by Hassey et al in triangulating disease codes with treatments and other findings has merit, but due consideration should have been given to existing literature

Philip J Bayliss Brown honorary senior lecturer in medical informatics

Department of Diabetes and Endocrinology, St Thomas's Hospital, King's College, London SE1 7EH

Phil@hicomm.demon.co.uk

1 Hassey A, Gerrett D, Wilson A. A survey of validity and utility of electronic patient records in a general practice. BMJ 2001;322:1401-5. (9 June.)

2 Hogan WR, Wagner MM. Accuracy of data in computerHogan WR, Wagner MM. Accuracy of data
based patient records. JAMIA 1997;4:342-55.

3 Brown PJB, Sönksen P. Evaluation of the quality of information retrieval of clinical findings from a computerinformation retrieval of clinical findings from a computerised patient database using
model. JAMIA 2000;7:401-12.

model. JAMIA 2000;7:401-12.
4 Brown PJB, Sönksen P, Price C, Young P. A standard for evaluating the retrieval performance of clinical terminologies. In: Lorenzi N, ed. Proceedings of the 1999 AMIA fall symposium. Philadelphia: Hanley and Belfus, 1999:1031

5 Gray J, Majeed A, Kerry S, Rowlands G. Identifying patients with ischaemic heart disease in general practice: cross sectional study of paper and computerised medical records. $B M J$ 2000;321:548-50.

\section{Methods of evaluation of electronic patient records entail dangers}

EDitor-Hassey et al indicate the need to validate electronic patient records in primary care. ${ }^{1}$ While findings are appropriately expressed in percentages as in this article, their EPR-Val toolkit yields incorrect confidence intervals. For the diabetes data, the calculated 95\% confidence intervals are incorrect on two counts. Incorrect use of the table total as the denominator in calculating standard errors results in intervals that are too narrow for sensitivity and positive predictive value. Furthermore, the traditional method is inferior, especially for proportions near $100 \%$. The table shows their results, recalculated using the traditional and the preferred Wilson method. ${ }^{2}$.

Even with large samples the traditional method can give impossible values exceeding $100 \%$, as for the positive predictive value here. The preferable Wilson method is available in confidence interval analysis software ${ }^{4}$ and for Microsoft Excel (www.uwcm.ac.uk/ epidemiology_statistics/research/statistics/ 
Results of Hassey et al calculated by three methods

\begin{tabular}{|c|c|c|c|c|}
\hline & \multirow[b]{2}{*}{ Estimate (\%) } & \multicolumn{3}{|c|}{$95 \%$ confidence interval } \\
\hline & & EPR-Val toolkit & Traditional method & Wilson method ${ }^{23}$ \\
\hline Sensitivity & 98.3 & 98.1 to 98.5 & 96.8 to 99.8 & 96.0 to 99.3 \\
\hline Specificity & 100 & 100.0 to 100.0 & 100.0 to 100.0 & 99.9 to 100.0 \\
\hline Positive predictive value & 99.3 & 99.3 to 99.4 & 98.4 to 100.3 & 97.5 to 99.8 \\
\hline Negative predictive value & 100 & 99.9 to 100 & 99.9 to 100.0 & 99.9 to 100.0 \\
\hline
\end{tabular}

newcombe.htm). We are disturbed by the dissemination of the inadequately tested EPR-Val software, which should be withdrawn immediately from bmj.com. Potential users should check new software using data with known answers, as errors are quite common

Furthermore, some of the measures displayed are redundant, whereas others, especially accuracy, are potentially misleading. The quoted accuracy of $99.9 \%$ conceals the fact that about one in 60 people diagnosed with diabetes is not coded as such on the database. There is a danger in using terms such as sensitivity, specificity, and predictive value, familiar from the clinical or screening context, in the validation of data. In the former situation, the gold standard is implicitly whether the individual really has the disease. In the context of data validation, these quantities measure how two parts of the record agree. Some of the 13302 patients whose records do not indicate "diabetes" would have diagnosable disease, if sought using systematic diagnostic criteria. We are concerned that clinicians and managers believe that such figures indicate the practice has successfully identified all prevalent diabetic patients and is managing them proactively.

The study showed that many diagnosed cases of asthma, iron deficiency anaemia, hypothyroidism, and ischaemic heart disease are not adequately identifiable within present standards of record keeping. It is helpful to show such deficiencies, complete the audit cycle, and correct them. But the converse is false: high sensitivity and specificity do not imply that all is well. High "accuracy" certainly does not. Even with improved consistency of record keeping for asthma, etc, practices could still have many patients with unidentified disease, just as for diabetes.

Robert G Newcombe senior lecturer in medical statistics

University of Wales College of Medicine, Cardiff CF14 4XN

Newcombe@cf.ac.uk

Douglas G Altman professor of statistics in medicine ICRF Medical Statistics Group, Centre for Statistics in Medicine, Institute of Health Sciences, Oxford OX3 7LF

d.altman@icrf.icnet.uk

Trevor N Bryant deputy director

Information and Computing Division, School of

Medicine, University of Southampton, MailPoint 820 ,

Southampton General Hospital, Southampton

SO16 6YD

T.N.Bryant@soton.ac.uk

1 Hassey A, Gerrett D, Wilson A. A survey of validity and utility of electronic patient records in a general practice. BMJ 2001;322:1401-5. (9 June.)

2 Wilson EB. Probable inference, the law of succession, and statistical inference. J Am Stat Assoc 1927;22:209-12.

3 Newcombe RG, Altman DG. Proportions and their differences. In: Altman DG, Machin D, Bryant TN, Gardner MJ.
Statistics with confidence. 2nd ed. London: BMJ Books, 2000:45-56.

4 Bryant TN. Computer software for calculating confidence intervals (CIA). In: Altman DG, Machin D, Bryant TN, Gardner MJ. Statistics with confidence. 2nd ed. London: BMJ Books, 2000:208-13.

5 Bland JM, Altman DG. Misleading statistics: errors in textbooks, software and manuals. Int J Epidemiol 1988;17. books, sc

\section{Authors' reply}

EDITOR-We agree with Bayliss Brown that sensitivity and positive predictive value are useful measures of the validity of electronic patient record systems. We gave references in our paper to other studies that have used these methods, and we believe that we have given due consideration to the relevant literature.

We did not use Cohen's $\kappa$ because we were concerned with its reliance on symmetric marginal distributions and difficulties interpreting the statistic. ${ }^{1}$ This was recognised by Cohen in the qualifying statistical $\mathrm{k}$ max, calculated by multiplying the marginal values of each column and row, and dividing by the total number of observations. The value is the maximum value that $\kappa$ could achieve in the given circumstances. Thus, $1-\kappa \max$ is the proportion of possibilities, excluding chance, which cannot be achieved as a consequence of differing marginals. There are no acceptable standards for balancing and interpreting $\kappa, \kappa \max , 1-\kappa$ max. Further difficulties have been noted in the literature, which increased our reluctance to use the statistic. ${ }^{2}$ We thought that the use of $\kappa$ would have led us into difficulties of interpretation at a time when our goal was to provide a simple, easily usable tool.

We are grateful to Newcombe et al for showing an error in our calculation of confidence intervals in the EPR-Val toolkit. We have already corrected the error and an updated version of the toolkit (EPR-Val2) is now available on bmj.com (www.bmj.com/ cgi/content/full/322/7299/1401/DC1).

We believe that there is no single best measure of validity for electronic patient records. Terms such as "accuracy" may be misleading, but the validity of electronic patient records has previously been reported by using sensitivity and positive predictive value as measures of completeness and accuracy, respectively. ${ }^{3}$ We recommend that in future studies, those measuring the validity of electronic patient records should say exactly what they mean by validity and state what measures they have calculated from their data. We have provided the ERP-Val2 toolkit to facilitate this process.

We do not claim that measures of the validity of electronic patient records reflect the true prevalence of any diagnostic condi- tion in the community, nor the effectiveness of our clinical management for these conditions. Our survey was designed to measure only the validity of the data we hold in the clinical records. The derived statistics TPFN ratio and DBFind 10000 are included to help healthcare workers understand how many true cases of the test condition remain undiagnosed in the database and help quantify the benefits of validating a clinical database for those conditions. Time will tell whether future researchers will find these measures useful.

Alan Hassey general practitioner

Fisher Medical Centre, Millfields, Skipton

BD23 1EU

David Gerrett senior research fellow

School of Health and Community Studies,

University of Derby, Derby DE22 3HL

Ali Wilson senior associate lecturer

Research School of Medicine, University of Leeds, Leeds LS2 9LN

1. Cohen JA. A coefficient of agreement for nominal scales. Educational Psychological Measurement 1960;20:37-45.

2 Maclure M. Willett WC. Misinterpretation and misuse of the Kappa statistic. Am J Epidemiol 1987;126:161-9.

3 Whitelaw FG, Nevin SL, Milne RM, Taylor RJ, Taylor MW, Watt AH. Completeness and accuracy of morbidity and repeat prescribing records held on general practice computers in Scotland. BrJ Gen Pract 1996;46:181-6.

\section{Patient passports would alert doctors to previous bone marrow transplantation}

EDITOR-Hammadieh et al intended their letter to alert doctors to the fact that patients who have had successful bone marrow transplantation have peripheral blood cells originating from the donated bone marrow and that results of cytogenetic studies of these blood cells will relate to the donor. ${ }^{1}$

Unfortunately, only one of the two cases in the letter (case 1) was a cytogenetic case, involving a bone marrow transplant from a donor of the opposite sex. Hammadieh et al rightly pointed out that in such cases a male will have a female karyotype. However, the other case (case 2) was not a cytogenetic case. DF508 mutations in cystic fibrosis are detected by molecular genetic techniques in a DNA laboratory. DNA extracted from a blood sample before bone marrow transplantation can be used subsequently only for DNA and molecular studies. These distinctions are important to prevent the collection of an incorrect specimen, the specimen going to the wrong laboratory, or an incorrect interpretation being placed on the result.

The message that successful bone marrow transplantation will change a person's genome is valid. To prevent confusion, the advice given was to obtain a sample of blood or skin and store it before transplantation. This seems impractical, expensive, and likely to be unsuccessful. Bone marrow transplantation entails many tests, and patients may be quite young at the time; an extra test is a considerable burden. Who pays for the storage is another issue. The most important point, however, is 
whether anyone would know in, say, 10 years' time that there was a specimen in a liquid nitrogen store: only the patient or the patient's original doctor might know this.

Communication between doctors and between doctor and patient is the best way to convey the history, which should reveal a previous bone marrow transplantation. In our centre a patient passport and education kit are provided for all patients undergoing bone marrow transplantation. This is given to both the patient's general practitioner and the patient or the patient's family, or both. It contains all the information about the management, what was done, dates, drug treatment, side effects, and results of tests. In this way, we aim to keep informed all those involved with the patient's health later in life.

Arabella Smith associate head, department of cytogenetics

Helen Somerville coordinator, late effects clinic Children's Hospital at Westmead, Locked Bag 4001 , Westmead NSW 2145, Australia

ellies@chw.edu.au

1 Hammadieh N, Sharif K, Masoud A, Spyros P, Ola B. Beware of cytogenetic results after successful bone marrow transplantation. BMJ 2001;323:285. (4 August.)

\section{Vocational rehabilitation}

\section{New training and funding strategies are needed}

EDITOR-In their editorial Disler and Pallant discussed vocational rehabilitation. ${ }^{1}$ Since the publication in 1991 of its survey of blind and partially sighted people in Britain ${ }^{1}$ the Royal National Institute for the Blind (RNIB) has been concerned about the lack of support for retention in employment in the United Kingdom. ${ }^{2}$ This publication raised awareness of the incidence of visually impaired people who gave up work after the onset of sight difficulties and remained unemployed.

In the early 1990s the RNIB funded a research and development project called "Disability Leave," which drew on the experience of 18 employers who piloted best practice retention policies developed during the life of the project. The final report of this project was published in $1995 .{ }^{3}$ It recommended that, where no employment solutions are found by employer and employee, a specialist employment adviser should be asked to carry out an initial assessment. If the employee needs a work break to make adjustments to work practices, this should be offered as disability leave, using the analogy of maternity leave. The disability leave research was available to influence government at the time of drafting the UK Disability Discrimination Act 1995.

Further development work carried out by the RNIB and Rehab UK resulted in publication of the Get Back series in 1999/2000. ${ }^{4}$ This is a series of checklists and guides developed to help employer, employee, and employment adviser work together on the assessment process. It includes specialist guides-for example, on working with people with brain injuries or visual impair- ment. The series can be viewed on the internet (www.rnib.org.uk/ew/getback.htm).

During the time in which this work has been carried out, an increase in awareness of the importance of good practice in employment retention at government level and among some large employers in the United Kingdom has been detectable. The next big step, however, has to be to develop training to a nationally recognised standard for those who work in rehabilitation and to develop funding strategies that encourage retention in preference to early retirement. The National Vocational Rehabilitation Association (NVRA) is lobbying government to this effect.

Gillian Paschkes-Bell research and development officer

Royal National Institute for the Blind, London W1N 6AA

gpaschkes-bell@rnib.org.uk

1 Disler PB, Pallant JF. Vocational rehabilitation. $B M /$ 2001;323:121-3. (21 July.)

2 Bruce I, McKennell A, Walker E. Blind and partially sighted adults in Britain: the RNIB survey. Vol 1. London: HMSO, 1991

3 Paschkes-Bell G, Da Cunha S, Hurry J. Adapting to chang when an employee becomes disabled. London: Royal National Institute for the Blind, 1996.

4 Paschkes-Bell G, ed. The Get Back! pack. London: Royal National Institute for the Blind, 1999, 2000. (Series of 10
Nate publications.)

Proposed national vocational rehabilitation institute is step in right direction

Editor-I endorse Disler and Pallant's proposal for a national vocational rehabilitation institute for the United Kingdom. ${ }^{1}$ The National Vocational Rehabilitation Association has provided a forum for practitioners working in disability and employment since 1992. Many of the issues that Disler and Pallant raise are close to our hearts.

The timing for such an initiative is good. In July 2000 the association arranged a meeting at Whitehall to look at the establishment of national occupational standards for those who work in this area. This was chaired by Margaret Hodge, member of parliament, and attended by representatives of disability organisations and the employment service. The result of this has been funding from the authority responsible for qualifications and curriculum for research into the needs for, and scope of, such qualifications. This work, carried out under the auspices of the Employment National Training Organisation, is under way, and details can be found on the organisation's website (www.empnto.co.uk/ projects/campag/index.htm). Information about the National Vocational Rehabilitation Association (NVRA) can be found at www.nvra.org.uk/

The National Vocational Rehabilitation Association is a voluntary body and can do only so much. A national institute for vocational rehabilitation could do much to address the "hit and miss" approach to disabled people's employment situation that exists now. I agree with the need to create a body of dedicated professionals within the existing healthcare and social work professions, but I make a plea not to forget all those who are working in this field in the voluntary and private sectors. The national occupational standards that we hope will result from the current review will be designed to cover those working across all sectors and improve the collaboration between all concerned parties.

Jonathan Leach chair

National Vocational Rehabilitation Association, Sandringham House, Heritage Gate, Oxford

OX4 5LB

jleach@brookes.ac.uk

1 Disler PB, Pallant JF. Vocational rehabilitation. BMJ 2001:323:121-3. (21 July.)

\section{Armed services may provide model}

Editor-Disler and Pallant discuss the dearth of vocational rehabilitation in the United Kingdom. ${ }^{1}$ Readers may be interested to learn of the well established system of vocational rehabilitation that exists within the British armed services.

Many of the 200000 service personnel follow physically demanding careers, which can be associated with a high incidence of injury. As a result, the defence medical services have gained extensive experience in returning patients to a high functional level through vocational rehabilitation.

The medical rehabilitation centre of the defence services at Headley Court celebrates its 50th anniversary this year. We are the last remaining rehabilitation unit for the three armed services and provide intensive, residential rehabilitation for up to 180 patients. Some 2000 service personnel attend annually, most of whom have complex musculoskeletal injuries sustained during sport and military training. Each patient follows an individualised exercise rehabilitation programme, performed in groups, with physiotherapy, occupational therapy, or other input as needed. Chronic low back pain accounts for $40 \%$ of all admissions.

Rehabilitation programmes vary, ranging from a five day initial assessment, with education and a home exercise programme, through a progression of three week courses of exercise rehabilitation at different functional levels, the highest of which culminates in an eight mile forced march carrying $25 \mathrm{~kg}$ $(55 \mathrm{lb})$. These courses provide the intensity of multidisciplinary rehabilitation that has been shown to be effective. ${ }^{2}$ Furthermore, this takes place in a military environment, with a positive approach, peer support, and a degree of social rehabilitation. Military patients are also generally motivated to recover, as their career prospects often depend on a return to full fitness, and they are encouraged to comply with their rehabilitation programme. These factors are likely to further improve their outcome. Of 807 such patients undergoing rehabilitation for chronic low back pain at the centre, only $5.2 \%$ were recommended for medical retirement.

Military medicine also has extensive experience in the grading of disability and has used the PULHHEEMS system of medical classification since 1946. PULHEEMS stands for physical capability, upper limbs, lower limbs, hearing (right and left), eyesight 
(right and left), mental function, and stability (psychological and emotional). This system allocates all service personnel a grade that reflects their functional ability and capacity for work. Service medical officers, who understand the demands of life in a military environment and work closely with their patients' employers, are able to influence directly a person's employability and recommend modifications and restrictions to their work until such time as they are fit to resume full duties.

There is, as Disler and Pallant report, a pressing need for better provision of vocational rehabilitation in the United Kingdom. Perhaps the military model could help industry, the insurance companies, and the NHS to achieve this.

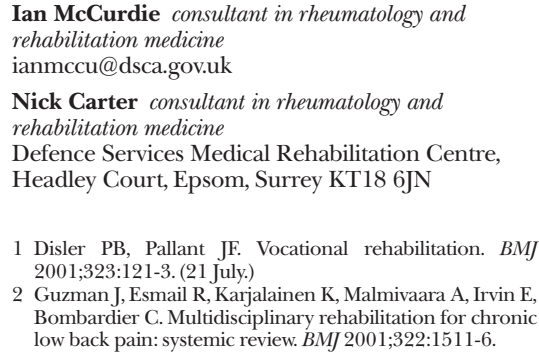

\section{Evidence based policy: don't be timid}

EDITOR-Black's discussion of the problems of evidence based policy seems to conclude that it is all very difficult. ${ }^{1}$ Without wanting to appear too gung-ho about the prospects for getting health managers and policymakers to use research more productively, I think that such timidity is not the best way forward. Researchers should be asserting the value - to policymakers and society - of the evidence they produce. They are already engaging with policymakers and other stakeholders to build the kind of "policy community" that Black concludes is needed.

Firstly, few people would argue with the principle that health policy should be evidence based-it should make full and proper use of research findings and research methods in policy development, implementation, and evaluation. But it is misleading to impute, as Black seems to, that this would mean that every policy decision should be based on research evidence and that other values or factors would be ignored. It simply means that research evidence plays its part alongside other influences in the policy process, when it has often been almost entirely absent in the past.

Secondly, Black sets up a mechanistic, linear model of research dissemination and implementation that no researcher or policymaker I know would support, and then proceeds to knock it down rather easily. Researchers and policymakers are not as naive and uninformed about each other's worlds as Black suggests, and one of the most encouraging trends of recent years has been the increasing dialogue and interplay between the two groups. Donald's commen- tary captures the sense of a change in the zeitgeist, towards a more evaluative, interactive, and symbiotic relation between research and health policy and practice. ${ }^{2}$

Thirdly, those who are interested in seeing the greater use of evidence in health policy and management decision making can learn much from the development of evidence based clinical practice. ${ }^{3}$ Black's paper is reminiscent of some of the early scepticism about evidence based medicine and the concerns expressed about its potential impact. Although the form of evidence based health policy and management may be very different from evidence based clinical practice, many of the underlying principles and lessons are eminently transferable.

Kieran Walshe senior research fellow

Health Services Management Centre, University of Birmingham, Birmingham B15 2RT k.m.j.walshe@bham.ac.uk

1 Black N. Bvidence based policy: proceed with care. Bu 2001;323:275-8. (4 August.)

Donald A. Commentary: research must be taken seriousl BMJ 2001;323:278-9. (4 August.)

Walshe K, Rundall T. Evidence based management: from theory to practice in healthcare. Milbank $O$ (in press).

\section{Declaring competing interests}

Problem cannot be solved by editors alone

EDITOR-Hussain and Smith have provided evidence of a small, but increasing proportion of articles declaring competing interests in a sample of selected medical journals. ${ }^{1}$ Krimsky, however, in a study including over 60000 articles from a much wider representation of scientific journals, found that competing interests were reported in less than $1 \%$ of articles, despite the policies endorsed by the journals. ${ }^{2}$

Both these data and those by Hussain and Smith are in striking contrast with a study that analysed 789 articles written by authors from Massachusetts universities and reported that, in about one out of three cases, at least one author had a vested interest in research. ${ }^{3}$ Even though the rates of disclosure are increasing as a result of more stringent editorial policies, they are still unacceptably low.

Furthermore, disclosure of competing interests is not even requested by many medical journals and scientific meetings, particularly in Europe. ${ }^{3}$ The main scope of many scientific meetings currently is apparently to sell the participants to the sponsor. ${ }^{4}$ It is curious, however, how disclosure, even when requested, is seldom endorsed to its full consequences. Few journals require disclosure of competing interests by reviewers or ask their editors to disclose their own interests. This could be particularly important in view of the increasing emergence of special interest groups, self selecting academic oligarchies with strong corporate ties that have key roles in academic settings, medical journals, and research agencies.

Disclosure of competing interests is simply a first, necessary, but insufficient step for a better credibility of medical information. It is not even practised. Other strategies are required, as described in detail elsewhere. ${ }^{4} \mathrm{~A}$ substantial problem in developing effective strategies towards a better control of competing interests in clinical medicine lies in the lack of recognition that this problem cannot be solved by medical editors alone.

Giovanni A Fava professor of clinical psychology Department of Psychology, University of Bologna, I-40127 Bologna, Italy fava@psibo.unibo.it

1 Hussain A, Smith R. Declaring financial competing interests: survey of five general medical journals. BMJ 2001;323:263-4. (4 August.)

2 Krimsky S. Journal policies on conflict of interest: if this is the therapy, what's the disease? Psychother Psychosom 2001;70:115-7

3 Krimsky S, Rothenberg LS, Stott P, Kyle G. Scientific journals and their authors' financial interests: a pilot study. Psychother Psychosom 1998;67:194-201.

4 Fava GA. Conflict of interest and special interest groups. Psychother Psychosom 2001;70:1-5.

\section{Types of competing interests would be of} interest

EDITOR-Lack of reporting of competing interests, as outlined by Hussain and Smith in their article, is probably most disturbing when it pertains to articles that have a major influence on decision making and clinical practice. ${ }^{1}$ For example, the low rate of reporting of competing interests in letters is unfortunate but probably not that disturbing, since letters rarely have a major impact on clinical practice, even if they express strong opinions. Editorials and original research are probably more influential, but the subject matter should also be taken into account. It makes a difference if the paper describes a randomised trial, a prognostic model, a case series, or a basic science report without any direct clinical promise.

We are therefore interested to know the rates of reporting of competing interests for specific categories of original papers and editorials at "high risk"-for example, those pertaining to randomised trials, decision analyses, cost effectiveness analyses, and meta-analyses of therapeutic and preventive interventions.

We examined the reporting of competing interests in guidelines of therapeutic and preventive interventions published in prestigious journals. ${ }^{2}$ The reporting rates were disappointingly low even for these influential publications. We would also be interested to know the specific competing interests reported in the 52 articles that mentioned something. ${ }^{1}$ Were they serious enough, or were the serious conflicts still undeclared? In our evaluation, most of the specific conflicts that were actually being declared entailed minor issues, such as travel expenses, speakers' honorariums, consultation, and such like. ${ }^{2}$ We hardly found authors (other than company employees) who had acknowledged being on the payroll of a company or owning company stock, despite the fact that both of these situations are probably not uncommon among high profile experts. Information on the types of competing interests disclosed is necessary to judge whether this sensitive issue has improved recently. 
Finally, it would be interesting to know whether there are specific variables, other than year of publication, associated with reporting of competing interests-for example, the number of authors or the source of funding for each publication. ${ }^{2}$

George N Papanikolaou research fellow

John P A Ioannidis chairman

jioannid@cc.uoi.gr

Clinical Trials and Evidence-Based Medicine Unit, University of Ioannina School of Medicine, Gr-Ioannina 45110, Greece

1 Hussain A, Smith R. Declaring financial competing interests. Survey of five general medical journals. $B M$ J 2001;323:263-4. (4 August.)

2 Papanikolaou GN, Baltogianni MS, ContopoulosIoannidis DG, Haidich AB, Giannakakis IA, Ioannidis JPA Reporting of conflicts of interest in guidelines of preventive and therapeutic interventions. BMC Med Res Methodol 2001;1:3.

\section{Breast feeding must consider HIV transmission in Latin America and the Caribbean}

EDITOR-Betrán et al's paper confirms the importance of exclusive breast feeding in reducing infant morbidity and mortality in the Latin American and Caribbean region. ${ }^{1}$ The authors did not, however, mention other cost effectiveness analyses of the promotion of breast feeding in Latin America that have been carried out.

In particular, through controlled designs Horton et al examined the effectiveness and cost of hospital based promotion of breast feeding in urban areas in three Latin American countries (Mexico, Honduras, and Brazil). ${ }^{2}$ They concluded that investing in the promotion of exclusive breast feeding and of any breast feeding is highly cost effective and should be part of the basic public health and clinical services packages of countries in the region.

This work highlighted the relevance of breastfeeding peer counsellors, which was confirmed in a subsequent experimental study in Mexico City. ${ }^{3}$ There, a threefold to fivefold increase in exclusive breastfeeding rates at 3 months post partum was achieved through prenatal and postnatal home visits by trained peer counsellors.

The AIDS pandemic has major implications for the promotion of breast feeding as HIV can be transmitted to children through breast feeding. The seroprevalence of HIV among women of reproductive age is relatively low in Latin America compared with sub-Saharan Africa and Asia but is relatively high in several Caribbean countries and some high risk areas of Latin America. Efforts to promote breast feeding in the region need to take into account the local epidemiology of the AIDS pandemic and available educational and therapeutic strategies for reducing the risk of vertical transmission of HIV from infected mothers to their children. ${ }^{4}$

Rafael Perez-Escamilla associate professor of nutritional sciences

University of Connecticut, Nutritional Sciences Department, Storrs, CT 06269-4017, USA

rperez@canr.uconn.edu
1 Betrán AP, de Onís M, Lauer JA, Villar J. Ecological study of effect of breast feeding on infant mortality in Latin America. BMJ 2001;323:303-6. (11 August)

2 Horton S, Sanghvi T, Phillips M, Fiedler J, Perez-Escamill R, Lutter C, et al. Breastfeeding promotion and priority setting in health. Health Policy Plan 1996;11:156-68.

3 Morrow AL, Guerrero ML, Shults J, Calva JJ, Lutter C, Bravo J, et al. Efficacy of home-based peer counselling to promote exclusive breastfeeding: a randomised controlle trial. Lancet 1999;353:1226-31.

4 Perez-Escamilla R. Promoting breast-feeding in the era of AIDS. Pan Am J Public Health 2001;9:357-61.

\section{Systematic reviews of evaluations of diagnostic and screening tests}

\section{Odds ratio is not independent of prevalence}

EDITOR-Deeks, in the third of four articles on evaluations of diagnostic and screening tests, promoted the odds ratio as often being constant regardless of the diagnostic threshold. ${ }^{1}$ We agree with Deeks's statement that the choice of threshold varies according to the prevalence of the disease. But the statement that the odds ratio is generally constant regardless of the diagnostic threshold can be misleading.

The value of an odds ratio, like that of other measures of test performance-for example, sensitivity, specificity, and likelihood ratios-depends on prevalence. ${ }^{2}$ For example, a test with a diagnostic odds ratio of 10.00 is considered to be a very good test by current standards. It is easy to verify that this is generally true only in populations at high risk. A diagnostic odds ratio of 10.00 in a low risk population may represent a very weak association between the experimental test and the gold standard test. This is so because the observable range of values for an odds ratio increases as the prevalence of the disease decreases (moves away from $1 / 2)$.

Nicole Jill-Marie Blackman senior biostatistician GlaxoSmithKline, 1250 South Collegeville Road, PO Box 5089, Collegeville, PA 19426-0989, USA nicole_blackman-1@gsk.com

\section{Deeks JJ. Systematic reviews of evaluations of diagnostic and screening tests. BMJ 2001;323:157-62. (21 July) \\ 2 Kraemer HC. The robustness of common measures of $2 \times 2$ association to bias due to misclassifications. American Statistician 1985;39:286-90.}

\section{Two issues were simplified}

EDITOR-We would like to draw attention to two points, which Deeks in his review article simplified.

Firstly, consider an example to illustrate the futility of what might be called the "reflex to fill the fourfold table" in research into diagnostic accuracy. Consider a study on an experimental test that claims to give clinicians more certainty in situations where they have only a few indications that disease may be present. But let us assume that the indications are not strong enough to justify the performance of truly invasive tests. Without the new experimental test these patients would be sent home. The value of the new test lies in its ability to identify those patients who have the disease and would benefit from treatment. In this scenario, the analysis of only those patients who test positively on the experimental test (two cells filled of the fourfold table) suffices to learn about its usefulness.

Secondly, Deeks ends his explanation of the application of the likelihood ratio by saying that knowledge of other characteristics of a particular patient that either increase or decrease their prior probability of endometrial cancer can be incorporated into the calculation by adjusting the pretest probability accordingly. This, however, assumes constancy of likelihood ratios, which should not be assumed because it is usually incorrect. In practice, the knowledge of other patient characteristics will have an influence on the magnitude of the likelihood ratios of following tests. This is so because when a chain of diagnostic tests (history taking, physical exam, lab tests, or imaging) is performed on a patient, certain results from his or her clinical history make the likelihood to find certain lab results more (or less) likely. This in turn influences the chances of finding certain imaging results. In other words, the results of the component tests are not mutually independent. For example, on average, women with a positive test on ultrasound (thickened endometrium) are more likely to test positively on hysteroscopy, in which the endometrial thickness is also assessed, albeit in a different manner.

The theoretical solution to this problem is the calculation of likelihood ratios that are conditional on the results of the preceding tests in the diagnostic test chain. In practice, this is usually not feasible owing to lack of data, and most investigators use logistic regression models to account for all these dependencies. These models, however, yield diagnostic odds ratios, not likelihood ratios. It is partly this complexity that hampers the application of simple diagnostic accuracy studies to clinical practice. In figure 2 the numerators in the second column of the right hand panel represent the number of false positives, not the true negatives.

Gerben ter Riet clinical epidemiologist Department of General Practice, Academic Medical Centre, University of Amsterdam, 1105 AZ

Amsterdam, Netherlands g.terriet@epid.unimaas.n

Alphons G H Kessels medical statistician Department of Clinical Epidemiology and Medical Technology Assessment, Maastricht University Hospital, 6202 AZ Maastricht, Netherlands

Lucas M Bachmann research fellow

Horten Centre, University of Zurich, CH-8091 Zurich, Switzerland

1 Deeks JJ. Systematic reviews of evaluations of diagnostic and screening tests. BMJ 2001;323:157-62. (21 July.)

\section{Uptake of antenatal screening for HIV infection can be high outside London too}

EDITOR-Cliffe et al point out that if the national target of an $80 \%$ reduction in vertical transmission of HIV is to be reached by December 2002 then rates of antenatal 
diagnosis of HIV infection must improve outside London.

Results from an unlinked anonymous survey of salivary dried blood spots suggest that Brighton and Hove is a low prevalence area, with an estimated two women with HIV infection giving birth each year. Since the introduction of routine antenatal testing $98 \%$ of women have agreed to HIV testing, and in the past 14 months HIV infection has been diagnosed in three women. All have accepted recommended interventions to reduce vertical transmission. Several factors seem to be contributing to the sustained high uptake:

- Before antenatal testing began a coordinator (MO) was appointed who was responsible for the planning and delivery of training to community midwives

- Close links have been maintained with the midwives since this initial period, and the service has had ongoing monitoring and evaluation

- Specific training for new and returning midwives has been provided

- Training is focused on attitudes and skills, reflecting the plethora of research showing that the belief of the midwife in HIV testing is key in a pregnant woman's decision to have the test.

We have shown that the Department of Health's target of a $90 \%$ uptake of antenatal HIV testing ${ }^{2}$ is achievable in low prevalence areas outside London. We hope that this example will inform practice in other areas, especially as-as Cliffe et al point out-over one quarter of pregnant women infected with HIV live outside London.

Gillian Dean HIV/genitourinary medicine consultant Martin Fisher HIV genitourinary medicine consultant Melanie Ottewill antenatal coordinator Claude Nicol Centre/Lawson Unit, Royal Sussex County Hospital, Brighton Healthcare Trust, Brighton BN2 5BE

gillian.dean@brighton-healthcare.nhs.uk

1 Cliffe S, Tookay PA, Nicoll A. Antenatal detection of HIV national surveillance and unlinked anonymous survey. BMJ 2001;323:376-7. (18 August.)

2 UK Health Departments. Targets aimed at reducing the number of children born with HIV:report from an expert group. London: Station

\section{Increasing email consultations may marginalise more people}

EDITOR-The explanations offered by Mechanic on why doctors feel stressed are both plausible and likely. ${ }^{1}$ As a general practitioner in the United Kingdom I am often at the receiving end of increased expectations of patients, as well as increasing guidance not only on how I should do more but also on how I should do it. I am thinking here, for example, of the guidelines from the National Institute for Clinical Excellence (NICE) and the national service frameworks.

I am, however, uncomfortable with Mechanic's proposed solution to the problem-namely, that doctors should spend more time consulting by email with their patients. In the United Kingdom internet access is related to socioeconomic class, with those living in a household headed by someone in a routine or semiroutine occupation accessing the internet less often compared with those living in households headed by someone in a managerial or professional occupation $(23-36 \%$ v $68-87 \%$ in a one month period). ${ }^{2}$ Although computer ownership has increased in the United Kingdom from 18\% in 1988 to 34\% 1998-9, certain groups of the population are less likely to own computers. The most important of these are people aged 60 and over (4\% ownership rate in 1998-9). ${ }^{3}$

Mechanic's proposed solution seems likely to marginalise old and poor people in favour of younger and socioeconomically advantaged people. It has long been recognised that those who need health care the most are least likely to receive it. ${ }^{4}$ By increasing the use of email consultations we may be at risk of using a cyber age solution that perpetuates an age old problem.

Geoff Wong general practice principal

The Surgery, London NW3 5BY

g.wong@pcps.ucl.ac.uk

Competing interests: None declared.

1 Mechanic D. How should hamsters run? Some observations about sufficient patient time in primary care. $B M$ 2001:323:266-8 (4 August.)

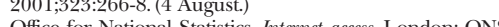
April 2001. (www.statistics.gov.uk/statbase/publication Asp?su=11\&B2A = Contents) (accessed 19 Aug 2001)

asp?su $=11 \& \mathrm{~B} 2 \mathrm{~A}=$ Contents) (accessed 19 Aug 2001).
Office for National Statistics. Households with selected 3 Office for National Statistics. Households with selected
consumer durables, 1972 to 1998-99: Social trends dataset consumer durables, 1972 to 1998-99: Social trends dataset
general household survey. (www.statistics.gov.uk/statbase/ xsdataset.asp) (accessed 19 Aug 2001).

4 Hart JT. The inverse care law. Lancet 1971;i:405-12.

\section{Moses baskets are a potential health hazard}

EDITOR-Moses baskets are commonly used items in households around the country. Some are fitted with carrying handles. Within two months in 2000 we encountered three cases of babies falling out of such baskets after an unintentional slip of the handles; two of these cases resulted in skull fractures. A possible diagnosis of nonaccidental injury was ruled out.

Close inspection of the Moses baskets showed that the handles did not seem long enough to meet in the middle (figure). This means that a tighter grip around the handles is needed, which increases the risk of an unintentional slip. The British Standards Institute has published guidelines on safety requirements on carrycots and stands but no specific standards on the length of handles have been defined. ${ }^{1}$ As a result of our correspondence, the British Baby Products Association has promised to raise the matter with CEN, the European Committee for Standardisation, where BS EN $1466: 1998$ is currently under review.

A literature search using Medline and the library of the Child Accident Prevention Trust did not identify any previously published reports about incidents involving Moses baskets. Several manufacturers did not seem to be aware of the problem. Nevertheless, a computer search of the home accident surveillance system, which is part of the Department of Trade and Indus-

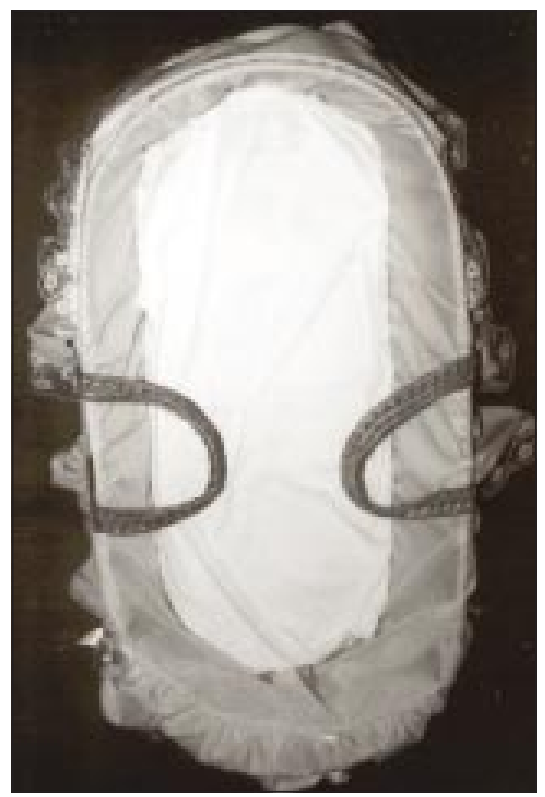

One of the Moses baskets involved in the three cases reported here, highlighting the distance between both handles when loosely put together in the middle

try, shows 24 reported cases in 10 years that were of a similar nature to ours. Taking into account that this database includes only reported cases and monitors only a fraction of the hospitals in the country, it is reasonable to assume that the real incidence of incidents involving Moses baskets may be much higher.

Most of the incidents involving a baby carrier will not result in any harm, especially as the babies concerned usually fall from a low height. Earlier this year a community based study showed an incidence of 22\% of falls of all types in premobile infants, with serious injuries occurring in less than $1 \%{ }^{2}$ By far the commonest site of injury seemed to be the head.

Our cases highlight the importance of raising awareness of parents, health professionals, and manufacturers of the potential health risks that Moses baskets can pose to babies.

M Hesseling specialist registrar mccannhesseling@btinternet.com

J A Sills consultant paediatrician

St Helens and Knowsley Hospital NHS Trust,

Whiston Hospital, Prescot L35 5DR

Competing interests: None declared.

1 British Standards Institute. Child care articles. Carry cots and stands. Safety requirements and tests. London: BSI, 1998. (BS EN 1466.)

2 Warrington SA, Wright CM, ALSPAC Study Team. Accidents and resulting injuries in premobile infants: data from the ALSPAC study. Arch Dis Child 2001;85:104-7.

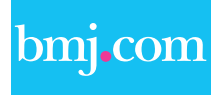

\section{Rapid responses}

Correspondence submitted electronically is available on our website 